\title{
ASSESSMENT OF TEMPOROMANDIBULAR DISORDER AND OCCLUSION IN TREATED CLASS III MALOCCLUSION PATIENTS
}

\author{
Karyna VALLE-COROTTI ${ }^{1}$, Arnaldo PINZAN ${ }^{2}$, Caio Vinícius Martins do VALLE ${ }^{3}$, \\ Ana Carla Raphaelli NAHÁS ${ }^{4}$, Mauro Vinícius COROTTI ${ }^{5}$
}

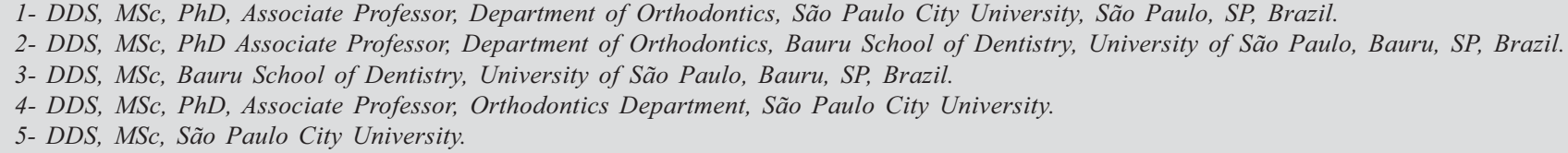

Corresponding Address: Karyna Martins do Valle-Corotti - Rua José Ferreira Marques 10-10 Apto 64 - 17012-200 Bauru SP, Brazil e-mail: vallek@uol.com.br

Received: June 09, 2006 - Modification: January 24, 2007 - Accepted: February 15, 2007

\begin{abstract}
$O$

bjective: The aims of this study were to compare the prevalence of temporomandibular disorders (TMD) in individuals submitted to either orthodontic or ortho-surgical Class III malocclusion treatment and to assess the influence of occlusal aspects on TMD severity. Material and methods: The sample consisted of 50 individuals divided into two groups, according to the type of treatment (orthodontic or orthodontic with orthognathic surgery). The presence of signs and symptoms of TMD was evaluated by an anamnestic questionnaire and a clinical examination, including TMJ and muscle palpation, active mandibular range of motion, joint noises and occlusal examination. Results: Based on the anamnestic questionnaire, $48 \%$ had no TMD, $42 \%$ had mild TMD and 10\% had moderate TMD. The presence and severity of TMD did not show any relationship with the type of orthodontic treatment $(\mathrm{p}>0.05)$. The chi-square test showed a positive association $(\mathrm{p}<0.05)$ between TMD and nonworking side occlusal interferences. Conclusion: Based on the methodology used and the results obtained, it may be concluded that Class III orthodontic treatment was not associated with the presence of TMD signs and symptoms and the non-working side contacts can be occlusal factors of risk. There was no significant difference in TMD prevalence between the studied groups (orthodontically treated patients and patients treated with orthodontics followed by orthognathic surgery).
\end{abstract}

Uniterms: Temporomandibular disorders; Temporomandibular joint dysfunction syndrome; Corrective orthodontics; Angle Class III malocclusion.

\section{INTRODUCTION}

The term "temporomandibular disorders" (TMD) refers to clinical alterations characterized by signs and symptoms involving the masticatory muscles or the temporomandibular joint (TMJ) or both ${ }^{30}$.

TMD have been studied since the beginning of the last century and became worldwide known when Costen ${ }^{4}$ published an article in 1934 describing a set of craniofacial symptoms designated as the Costen Syndrome. The great drive in epidemiologic studies on TMD came about with Helkimo ${ }^{13,14}$, who developed a clinical index and an anamnestic index that quantitatively measured the severity of TMD symptoms. As the effectiveness of the assessment method used in epidemiologic studies was proved ${ }^{11}$, an attempt was made to establish the prevalence of TMD in the population.

Conti, et al. ${ }^{3}(1996)$, in a sample of 310 young persons with mean age of 18.8 years, observed a prevalence of mild, moderate and severe TMD of $49.35 \%, 10.32 \%$ and $0.97 \%$, respectively. These authors concluded that, although TDM prevalence was relatively high, the need for treatment (moderate and severe TMD) in the surveyed population was $11.29 \%$. Similar results were found by Conti, et al. ${ }^{2}(2003)$ and Valle-Corotti, et al. ${ }^{28}$ (2003), in a population of 200 patients with Class I and II malocclusion, with and without orthodontic treatment. The results of these studies ${ }^{2,28}$ showed absence of TMD in $62.5 \%$ of the patients, mild TMD in $34 \%$ and moderate TMD in $3.5 \%$, which indicates that a small portion of the surveyed population required treatment for the dysfunction.

Differents aspects of functional occlusion was 
investigated in cases of TMD include: the deviation between the centric relation (CR) position and the habitual maximum intercuspation (HMI) position, contacts on the working and non-working sides, absence of lateral or protrusive guides and interference in the disocclusion guides. While assessing the functional occlusion, Bell, et al. ${ }^{1}$ (2002) suggested that occlusal interference may be considered as an etiologic factor of TMD.

Malocclusion has been associated with TMD, when it is believed that the alteration of form might cause alteration in the stomatognathic system function ${ }^{29}$. With the intention of elucidating this relation, several authors have studied Class I, II malocclusion ${ }^{6,18}$, posterior crossbite ${ }^{6}$ anterior open bite $^{6,16}$, horizontal overlap ${ }^{20}$ and vertical overlap ${ }^{22}$, suggesting that these alterations are responsible for the onset of TMD symptoms. Orthodontic treatment has also been associated with TMD, and considered as a cause $\mathrm{e}^{30}$, cure $^{29}$ or a preventive factor ${ }^{5}$ of dysfunctions for changing the patient's occlusal pattern. Treatment of Class III malocclusion in adult patients may be compensatory or associated with orthognathic surgery and this approximates surgery to a possible inter-relation with TMD.

The literature demonstrates that ortho-surgical management of Class III skeletal malocclusion may present favorable effects on TMD on mandibular function ${ }^{24,27}$. This improvement in TMJ condition may be related to the type of osteotomy performed ${ }^{16}$ or to the type of fixation used ${ }^{10}$. The literature does not, however, refers to the TMD index in a population treated for Class III malocclusion.

The aims of this study were to compare the prevalence of temporomandibular disorders (TMD) in individuals submitted to either orthodontic or ortho-surgical Class III malocclusion treatment and to assess the influence of occlusal aspects on TMD severity.

\section{MATERIAL AND METHODS}

\section{Study Population}

The population studied of this study comprised patients treated by $\mathrm{PhD}$ and Master's degree graduate students from Bauru School of Dentistry (FOB), University of São Paulo $(\mathrm{n}=21$ patients $)$ and patients treated by Dr. Laurindo Zanco Furquim at his private clinic in the city of Maringá, PR, Brazil $(n=29$ patients). In both cases, initial patient selection was based of the review of clinical dental records. The patients were fully informed on the objectives of the study and signed a written informed consent form, in compliance with the 196/96 Resolution of the Brazilian National Health Council. The ortho-surgical cases were treated by the same two surgeons in both cities.

Inclusion criteria were: bilateral Class III molar relationship and presence of all teeth up to the first molars as observed on the dental casts before treatment; and presence of all teeth up to the first molars during the clinical exam (except for the cases of extractions for orthodontic purposes). The study population, which was assessed art least 1 year after completion of the orthodontic treatment, was assigned to 2 groups: Group I: 25 young persons, submitted to orthodontic treatment to correct Class III malocclusion; Group II: 25 young persons, submitted to ortho-surgical treatment to correct Class III malocclusion.

\section{Questionnaire Application}

The patients filled out a chart containing personal information (name, age, gender, address, telephone) and questions about symptoms relative to TMD (anamnestic questionnaire). This questionnaire was developed on the basis of pre-existent charts ch $^{3,-9}$ and applied to the patients without the examiner's interference, not to create an expectation, which could influence the results of the clinical exam to be performed. The patients answered 10 questions relative to symptoms, which allowed classifying each case with respect to the degree of dysfunction.

\section{Anamnestic Questionnaire}

1. Do you find it difficult to open your mouth?

2. Do you find it difficult to move your jaw sideways?

3. Do you feel discomfort or muscular pain on chewing?

4. Do you have frequent headaches?

5. Do you have pain in the neck and/or shoulders?

6. Do you have earache or pain close to your ears?

7. Do you notice any TMJ noise?

8. Do you consider your bite "normal"?

9. Do you chew on only one side of your mouth?

10. Do you have facial pain on waking?

The following possible answers were offered: "yes", "no" or "sometimes" Each "yes" was scored 2, "sometimes" was scored 1 and "no" was scored 0. Questions 4,6 and 7 received score 3 when the answer "yes" corresponded to bilateral or intense symptoms, score 2 if it corresponded to unilateral or mild, score 1 if it meant sometimes. The sum of the scores obtained allowed classifying the sample as regards TMD, based on the following score scale, in accordance with Conti, et al. $^{3}$ (1996) scores from 0 to 3 - non-TMD patient; scores from 4 to 8: - mild TMD patient; scores from 9 to 14 - moderate TMD patient; scores from 15 to 23 : severe TMD patient.

\section{Physical Exam}

The physical exam was performed by a single professional. TMJ was examined by palpation of the lateral and posterior aspects; maximum, lateral and protrusion mandibular movements; and observation TMJ noises.

The muscular exam consisted of bilateral palpation of the temporal muscles (posterior, medial and anterior) superficial masseter (origin, medial and posterior) deep masseter, sternocleidomastoid and trapezium (superior) muscles.

The dental and occlusal exams included assessment of overbite and overjet, maxillomandibular relationship (CR and $\mathrm{MHI}$ ), presence and type of lateral and anterior guides, interference on the non-working side and number of tooth contacts in MHI. These data were considered as variables for a posterior comparison with TMD index. 


\section{Statistical Analysis}

The non-parametric data were analyzed statistically by Mann-Whitney U test, which assessed the inter-group differences of the TMD index. Student's t-test for parametric analysis assessed data referring to age, mouth opening, laterality, horizontal and vertical protrusion overlap. Chisquare test was applied to assess the association between the TMD index and the other conditions evaluated in this investigation.

\section{RESULTS}

The study population presented a mean age of 25.8 years. Group I (orthodontically treated patients) had a mean age of 24.7 years and Group II (patients treated with orthodontics followed by orthognathic surgery) had a mean age of 26.9 years.

Gender distribution in the sample was $36 \%$ (18) men and $64 \%$ (32) women.

Classification of the anamnestic index for the whole sample was performed by the sum of the scores of the answers to items of the anamnestic questionnaire: absent TMD , - 48\%; mild TMD - 42\%; Moderate TMD - 10\%. No patient was found to have severe TMD.

The anamnestic index was also applied to each studied group with respect to the presence and/or severity of TMD (Figure1).

When the Mann-Whitney test was applied, no statistically significant difference $(\mathrm{p}=0.40)$ was fund between the groups (Table 1).

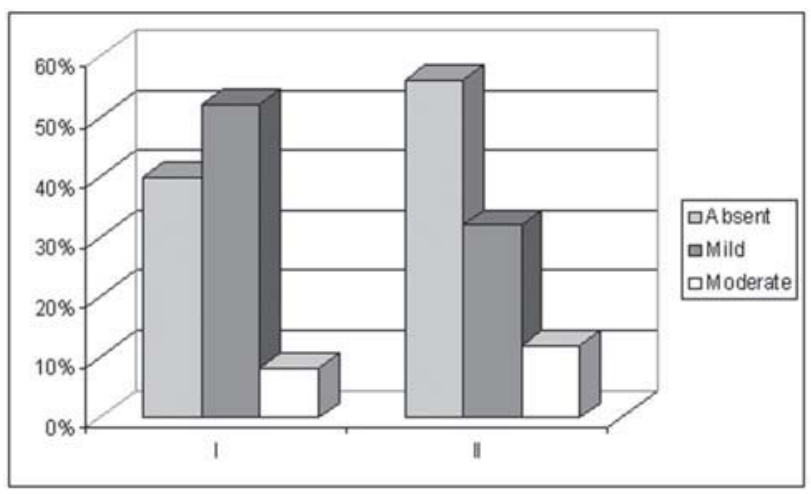

FIGURE 1- TMD index in Group I (orthodontically treated patients), and Group II (patients treated with orthodontics followed by orthognathic surgery)
The only variable that showed a statistically significant association with the TMD index was "interference in the non-working side (right and left)" ( $\mathrm{p}=0.02$; chi-square test), which was characterized by the impossibility of performing lateral disocclusion guide (Figure 2).

\section{DISCUSSION}

The study of the effects of orthodontic treatment on TMD began to attract greater attention from orthodontists when the appearance of TMD signs and symptoms to orthodontic treatment, were filed ${ }^{30}$.

In the present study, the treatment of dental and skeletal alterations was studied in accordance with the different therapeutic approaches (either orthodontic and/or surgical management). The study population was divided into two groups: one treated orthodontically and the other treated with orthodontics followed by orthognathic surgery, which enable comparing the different treatments and the associated presence and/or severity of TMD signs and symptoms.

The anamnestic questionnaire applied in this study was answered in a self-applicable manner by all the patients. The TMD index (absent, mild and moderate) was obtained by the sum of the scores attributed to the answers to this questionnaire. The reliability of $95 \%$ of TMD classification obtained by the anamnestic questionnaire was demonstrated by Fonsêca ${ }^{11}$ (1992) and confirmed by Hesse, et al..$^{15}$ (1997), who reported a high correlation $(\mathrm{p}=0.0003)$ among the answers to the questionnaire and the clinical findings. This questionnaire represents a simplified form of assessment

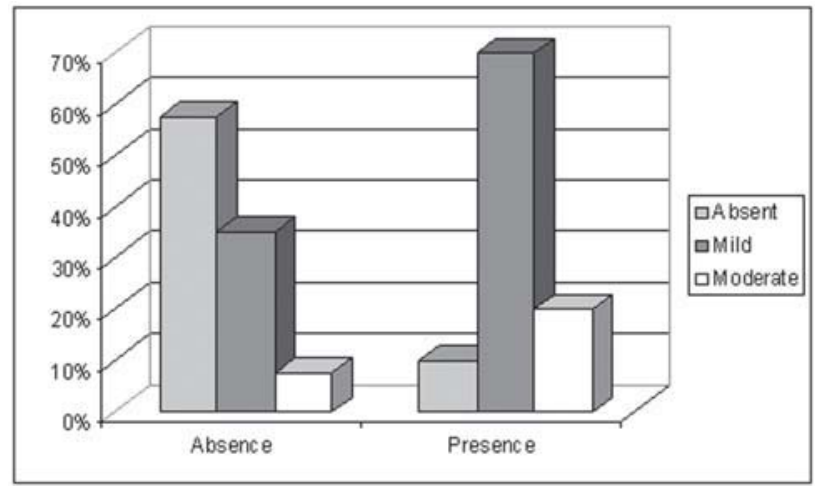

FIGURE 2- Non-working side occlusal contacts and TMD index

TABLE 1- Non-working side occlusal contacts and TMD index

\begin{tabular}{lllll}
\hline \multirow{2}{*}{ Non-working occlusal contacts } & Absent & Mild & Moderate & Total \\
\hline Absent & & & \\
Present & $57.5 \%(23)$ & $35 \%(14)$ & $7.5 \%(3)$ & $100 \%(40)$ \\
\hline & $10 \%(1)$ & $70 \%(7)$ & $20 \%(2)$ & $100 \%(10)$ \\
\hline
\end{tabular}

(n) Number of individuals. * Statistically significant association. 
when compared to the clinical exam and may be incorporated to the initial orthodontic exam ${ }^{12}$, complementing the orthodontic documentation, as its information is precise and extremely important to the orthodontist.

The results showed that in the 2 groups studied, $48 \%$ of the sample was found to be without TMD; mild TMD was found in $42 \%$ and moderate TMD was diagnosed in $10 \%$, whereas no severe TMD was found in any patient, irrespective of the group. These values were obtained in accordance with the index proposed and modified by other authors ${ }^{11,13,14}$. In terms of the need for treatment, it is accepted that only patients with moderate to severe TMD require direct intervention, while patients with light TMD predominantly need guidance and self-knowledge $\mathrm{e}^{3,11}$.

In this study, the number of patients with some degree of TMD ( $n=26)$ was similar to that of patients without TMD $(n=24)$, and no statistically significant differences were found between these results.

Considering the entire sample, $52 \%$ of the patients presented some degree of TMD, which demonstrates how common TMD signs and symptoms are and how neglected they might be by orthodontists because all individuals examined in this study had been treated for malocclusion and continued to present TMD. The orthodontist must know how to diagnose the signs and symptoms of TMD, to explain them to the patient and to provide guidance, irrespective of the patient's stage of treatment. Due to the long duration of orthodontic treatments, 2 years on average, non-diagnosed or misdiagnosed signs and symptoms of TMD might bring displeasure to the orthodontist in addition to generating legal claims that would cause moral and financial damage. In this study, $10 \%$ of the patients presented TMD, which is agreement with the findings of previous studies that found $10.5 \%$ of individuals with moderate and severe $\mathrm{TMD}^{29}$ and $10.3 \%$ with moderate $\mathrm{TMD}^{3}$. The prevalence of individuals with mild TMD (42\%) is close to outcomes reported by Dahl, et al. ${ }^{5}$ (1988), which were $43.1 \%$ prevalence among orthodontically treated patients and $40 \%$ among non-TMD patients (control group). These data demonstrate a similar prevalence among populations either submitted to orthodontic treatment or not.

The positive effects of orthognathic surgery as regards TMD have been mentioned in the literature ${ }^{16,19}$. In this study, the groups behaved in a similar manner in relation to the TMD index, and no advantages were observed in the surgically managed group. However, this affirmation would have a sounder basis if a comparison were made with a group of non-treated individuals, or if the study were longitudinal. In this study, $60 \%$ of Group 1 and $48 \%$ of Group II presented some degree of TMD. Although small, perhaps this difference might be attributed to a beneficial effect of orthognathic surgery.

The basis of this study was the use of an anamnestic questionnaire which, in a simplified manner, indicated the presence and severity of TMD. This questionnaire is an important indicator to orthodontists. Although these professionals might not apt to treat TMD, they should at all times be at least capable of diagnosing its signs and symptoms.

Though different occlusal characteristics were evaluated, only the interferences on the non-working side presented association with the TMD index, as in accordance with the literature, they are considered as potentially traumatic and capable of causing damage to the stomatognathic system ${ }^{21}$.

Table 1 and Figure 2 show that the presence of interference on the non-working side differed significantly in relation to the TMD index. Of the 10 patients with interference, 9 presented with some degree of TMD; however, only 2 individuals with moderate TMD required some type of treatment. This association between occlusal interference and TMD is mentioned in the literature ${ }^{19}$, but the mechanism of this relation remains unclear. It cannot be affirmed, however, that interference represents a determinant factor for developing TMD because patients in this investigation and in other studies ${ }^{23}$ who present occlusal interference and absence of TMD. This non-association between occlusal interferences and TMD is perhaps explained by the masticatory system's capacity of adapting to the occlusal situation $^{17,18}$. Occlusal interferences may, however, cause local damage, such as wear facets, localized overload in a single tooth and also individual periodontal alterations that cause tooth mobility. These alterations may go unnoticed for years and become serious on a long-term basis. The presence of parafunctional habits may be one of the factors that make patients with interferences develop $\mathrm{TMD}^{24}$. Nevertheless, this relationship was not assessed in study.

Occlusal interferences must be corrected during orthodontic treatment by altering the torque or coordinating the arches, or even at the end of treatment, with the performance of oclusal adjustment, as the absence of this type of contact represents one of the requirements of the ideal occlusion ${ }^{15}$.

\section{CONCLUSION}

Based on the methodology used and the results obtained, it may be concluded that Class III orthodontic treatment was not associated with the presence of TMD signs and symptoms and the non-working side contacts can be occlusal factors of risk. There was no significant difference in TMD prevalence between the studied groups (orthodontically treated patients and patients treated with orthodontics followed by orthognathic surgery).

\section{REFERENCES}

1- Bell YL, Jamsa T, Korri S, Niemi PM, Alanen P. Effect of artificial occlusal interferences depends on previous experience of temporomandibular disorders. Acta Odontol Scand. 2002;60(4):21922

2- Conti A, Freitas M, Conti P, Henriques J, Janson G. Relationship between signs and symptoms of temporomandibular disorders and orthodontic treatment: a cross-sectional study. Angle Orthod. $2003 ; 73(4): 411-7$ 
3- Conti PCR, Ferreira PM, Pegoraro LF, Conti JV, Salvador MC. A cross-sectional study of prevalence and etiology of signs and symptoms of temporomandibular disorders in high school and university students. J Orofac Pain. 1996;10(3):254-62.

4- Costen JB. A syndrome of ear and sinus symptoms dependent upon disturbed functions of TMJ. Ann Otol Rhinol Laryngol. 1934;43(1):115

5- Dahl BL, Krogstad BS, Ogaard B, Eckersberg T. Signs and symptoms of craniomandibular disorders in two groups of 19-year-old individuals, one treated orthodontically and other nor. Acta Odontol Scand. 1988;46(2):89-93.

6- Dahlberg G, Petersson A, Westesson PL, Eriksson L. Disk displacement and temporomandibular joint symptoms in orthognathic surgery patients. Oral Surg Oral Med Oral Pathol Oral Radiol Endod. $1995 ; 79$ (3):273-7.

7- Egermark-Eriksson I; Thilander B. Craniomandibular disorders with special reference to orthodontic treatment: an evaluation from childhood to adulthood. Am J Orthod Dentofac Orthop. 1992;101(1):28-34

8- Egermark-Eriksson I, Carlsson GE, Magnusson T. A long-Term epidemiologic study of the relationship between occlusal factors and mandibular dysfunction in children and adolescents. J Dent Res. 1987;66(1):67-71.

9- Egermark-Eriksson I, Magnusson T, Carlsson GE. A 20-year followup of signs and symptoms of temporomandibular disorders and malocclusions in subjects with and without orthodontic treatment in childhood. Angle Orthod. 2003;73(2):109-15.

10- Fienerman DM, Piecuch JF. Long-term effects of orthognathic surgery on the temporomandibular joint: comparison of rigid and non-rigid fixation methods. Int $J$ Oral Maxillofac Surg. $1995 ; 24(4): 268-72$.

11- Fonsêca DM. Disfunção craniomandibular (DCM): elaboração de índice anamnésico [dissertação]. Bauru (SP): Faculdade de Odontologia de Bauru, Universidade de São Paulo; 1992.

12- Hans MG, Lieberman J, Goldberg J, Rozencweig G, Bellon E. A comparison of clinical examination, history, and magnetic resonance imaging for identifying orthodontic patients with temporomandibular joint disorders. Am J Orthod Dentofacial Orthop. 1992;101(1):549.

13- Helkimo M. Studies on function and dysfunction of the masticatory system. I. An epidemiological investigation of symptoms of dysfunction in Lapps in north of Finland. Proc Finn Dent Soc. 1974;70(4):37-49.

14- Helkimo M. Studies on function and dysfunction of the masticatory system. II. Index for anamnestic and clinical dysfunction and occlusal state. Sven Tandlak Tidskr. 1974;67(2):101-21.

15- Hesse JR, Van Loon LAJ, Naeije M. Subjective pain report and the outcome of several orthopedic tests in craniomandibular disorder patients with recent pain complaints. J Oral Rehabil. 1997;24:4839.

16- Hu J, Wang D, Zou S. Effects of mandibular setback on the temporomandibular joint: a comparison of oblique and sagittal splint ramus ostectomy. J Oral Maxillofac Surg. 2000; 58(4):375-81.

17- Ingervall B, Carlsson GE. Masticatory muscle activity before and elimination of balancing side occlusal interference. J Oral Rehabil. 1982;9(3):183-92.
18- Karlson S, Cho SA, Carlsson GE. Changes in mandibular masticatory movements after insertion of nonworking-side interference. J Craniomandib Disord. 1992;13(4):177-83.

19- Kim M, Graber TM, Viana MA. Orthodontics and temporomandibular disorder: a meta-analysis. Am J Orthod Dentofacial Orthop. 2002;121(5):438-46.

20- Korioth TWP. Number and location of occlusal contacts in intercuspal position. J Prosthet Dent. 1990;64(2):206-10.

21- McNeill C, editor. Craniomandibular disorders: guidelines for evaluation, diagnosis, and management. Chicago: Quintessence;1990.

22- Lieberman MA, Gazit E, Fuchs C, Lilos P. Mandibular dysfunction in 10-18 year old school children as related to morphological malocclusion. J Oral Rehabil. 1985;13(3):209-14.

23- Magnusson T, Enbon L. Signs and symptoms of mandibular dysfunction after introduction of experimental balancing-side interferences. Acta Odontol Scand. 1984;42(3):129-35.

24- Nagamine T, Kobayashi T, Nakajima T, Hanada K. The effects of surgical-orthodontic correction of skeletal class III malocclusion on mandibular movement. J Oral Maxillofac Surg. 1993;51(4):3859 .

25- Nilner M. Relationships between oral parafunctions and functional disturbances and diseases of the stomatognathic system among $15-$ to -18 year olds. Acta Odontol Scand. 1983;41:197-201.

26- Okeson JP. Management of temporomandibular disorders and occlusion. 4. ed. Saint Louis: Mosby; 1998.

27- Panula K, Somppi M, Finne K, Oikarinen K. Effects of orthognathic surgery on temporomandibular joint dysfunction. Int $\mathrm{J}$ Oral Maxillofac Surg. 2000;29(3):183-7.

28- Valle-Corotti KM, Pinzan A, Conti PCR, Janson GRP. Estudo comparativo da oclusão e da sua relação com as Disfunções Temporomandibulares (DTM) em jovens com e sem tratamento ortodôntico. Rev Dent Press Ortodon Ortopedi Facial. 2003;8(6):6171.

29- Wigdorowicz-Makowerowa N, Grodzki C, Panek H, Maslanka T, Plonka K, Palacha A. Epidemiologic studies on prevalence and etiology of functional disturbances of the masticatory system. J Prosthet Dent. 1979;41(1):76-82.

30- Wyatt, WE. Preventing adverse effects on the temporomandibular joint through orthodontic treatment. Am J Orthod Dentofacial Orthop. 1987;91(6):493-9. 